\title{
Aplicação de auxinas e incisão anelar em pessegueiros cv. sentinela ${ }^{1}$
}

\author{
Application of auxins and girdling on cv. sentinela peachs
}

Ivar Antonio Sartori ${ }^{2}$ Denis Salvati Guerra ${ }^{3}$ Gilmar Arduino Bettio Marodin ${ }^{4}$

\section{RESUMO}

Com o objetivo de antecipar elou aumentar o tamanho dos frutos, do pessegueiro "Sentinela" na região da Depressão Central do RS, com intuito de evitar o pico de produção em um curto periodo de tempo, foram realizadas aplicações de duas auxinas de síntese 3,5,6 -TPA (ácido 3,5,6tricloropiridiloxiacético) na formulação ácido livre e 2,4-DP (ácido 2,4-diclorofenoxipropionico) na formulação éster $e o$ uso da técnica da incisão anelar em ramos. A avaliação foi realizada no ano de 1998, na Estação Experimental Agronômica da Universidade Federal do Rio Grande do Sul (UFRGS), situada em Eldorado do Sul, RS, à latitude 30³9'S e longitude $51^{\circ} 06^{\prime} \mathrm{W}$. O delineamento experimental foi de blocos casualizados com quatro repetições e uma planta por parcela. Os tratamentos foram efetuados na fase de lignificação do endocarpo - estádio II - no dia 17/09/99, em plantas previamente submetidas ao raleio manual de frutos: 1) 3,5,6TPA $10 \mathrm{mg} \mathrm{L}^{-1}$; 2) 3,5,6-TPA $20 \mathrm{mg} \mathrm{L}^{-1}$; 3) 3,5,6-TPA $30 \mathrm{mg} \mathrm{L}$ ${ }^{\prime}$; 4) 3,5,6-TPA $20 \mathrm{mg} \mathrm{L}^{-1}+$ incisão anelar; 5) 2,4-DP $25 \mathrm{mg} \mathrm{L}$ ; 6) 2,4-DP $50 \mathrm{mg} \mathrm{L}^{-1}$; 7) 2,4-DP $75 \mathrm{mg} \mathrm{L}^{-1}$; 8) 2,4-DP $50 \mathrm{mg}$ $L^{-1}+$ incisão anelar; 9) Incisão anelar e 10) Testemunha. Os tratamentos com auxinas e incisão anelar não aumentaram o peso total de frutos por planta, nem o peso médio dos frutos, mas os tratamentos com auxinas, especialmente o 3,5,6 TPA $20 \mathrm{mg} \mathrm{L}^{-1}$, com incisão anelar ou não, anteciparam a maturação em cerca de 15 dias. Os tratamentos não afetaram a qualidade dos frutos em termos de firmeza de polpa. O teor de sólidos solúveis totais não foi afetado de forma evidente pela aplicação das duas auxinas e uso da técnica da incisão anelar em ramos.

Palavras-chave: Prunus persica, antecipação da maturação, qualidade de fruto, auxinas.

\section{ABSTRACT}

With the objective of advancing crop and increasing the final size of the fruit of cultivating of peach tree Sentry in the area of the Central Depression of RS, applications of two synthesis auxin were accomplished 3,5,6 -TPA (acid 3,5,6 - tricloropiridiloxiacético) and 2,4-DP (acid 2,4diclorofenoxipropionico) and the use of the incision to pant in branches. The evaluation was accomplished among the agricultural years of 1998 and 1999, in the Agronomic Experimental Station of the Federal University of Rio Grande do Sul (UFRGS), located in Eldorado of the South, RS to the latitude $30^{\circ} 39^{\prime} \mathrm{S}$ and longitude $51^{\circ} 06^{\prime} \mathrm{W}$. The experimental design was of blocks randomized with four repetitions and

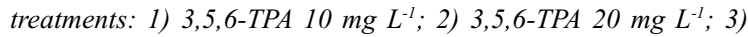
3,5,6-TPA $30 \mathrm{mg} \mathrm{L}^{-1}$; 4) 3,5,6-TPA $20 \mathrm{mg} \mathrm{L^{-1 }}+$ inisão to pant; 5) 2,4-DP $25 \mathrm{mg} \mathrm{L}^{-1}$; 6) 2,4-DP $50 \mathrm{mg} \mathrm{L}^{-1}$; 7) 2,4-DP $75 \mathrm{mg} \mathrm{L}$ ; 8) 2,4-DP $50 \mathrm{mg} \mathrm{L^{-1 }}+$ anelamento; 9) incision to pant and 10) Witness. The treatments were made in the phase of lignification of the endocarp - stadium II - in the days in plants previously submitted to the manual fruit thinning on the 17/09/

${ }^{1}$ Pesquisa apoiada pela CAPES, CNPq/PROPESQ, Universidade Federal do Rio Grande do Sul (UFRGS)

${ }^{2}$ Engenheiro Agrônomo, MSc. em Fitotecnia pela Faculdade de Agronomia, UFRGS e Bolsista da CAPES. Rua Barão do Triunfo, 718/702, fone: (0xx51) 3223-0426, 90130-100, Porto Alegre, RS. E-mail: ivar@vortex.ufrgs.br. Autor para correspondência. ${ }^{3}$ Estudante de Graduação da Faculdade de Agronomia - UFRGS. Bolsista de Iniciação Científica do PIBIC/CNPq. Av. Bento Gonçalves 7712, CP 776, 91501 970, Porto Alegre, RS. E-mail: denissalvatiguerra@zipmail.com.br

${ }^{4}$ Engenheiro Agrônomo, Doutor, Professor Adjunto do Departamento de Horticultura e Silvicultura, Faculdade de Agronomia UFRGS. Av. Bento Gonçalves 7712, CP 776, 91501 970, fone (0xx51) 3316-6020, Porto Alegre, RS. E-mail; marodin@vortex.ufrgs.br. 
99. Already for the treatments with auxins, especially 3,5,6 TPA $20 \mathrm{mg} \mathrm{L}^{-1}$ with incision to pant or they didn't advance the crop about 15 days. The treatments did not affect the quality of the fruits in terms of pulp firmness. The Tenor of Total soluble Solids (tenor of sugar) in a way not very egg white, not evidencing to your influences in the tenor of sugar of the fruit.

Key words: Prunus persica, crop precocity, ripinig maturity, fruit quality, auxins,

\section{INTRODUÇÃO}

A produção mundial de pêssegos e nectarinas, no ano de 2000, foi da ordem de 13,8 milhões de toneladas. Dentre os principais produtores mundiais, encontram-se a China, a Itália, os Estados Unidos e a Espanha com 4,12; 1,73; 1,42 e 1,09 milhões de toneladas, respectivamente. O Brasil aparece como o $13^{\circ}$ produtor mundial de pêssego com $155 \mathrm{mil}$ toneladas (FAO, 2000). O Rio Grande do Sul destacase como o maior produtor nacional com aproximadamente 70 mil toneladas de pêssegos, sendo que a Metade Sul do Estado possui mais de 7 mil hectares, correspondendo a $50 \%$ da produção gaúcha. Os demais Estados brasileiros que se sobressaem na produção de pêssegos são SP, PR e MG. No entanto, o Brasil ainda é um grande importador de frutas de caroço, tendo importado entre os anos de 1997 e 1999, mais de 600 mil dólares de frutas frescas (MARODIN $\&$ SARTORI, 2000).

O consumo de pêssegos no Brasil ainda é pequeno, pois se consome apenas $0,85 \mathrm{~kg}$ por habitante/ ano. Esse baixo consumo é explicado, em grande parte, pelo reduzido poder aquisitivo da população e também pela falta de investimentos em propaganda e em esclarecimentos ao consumidor, que considera o pêssego ainda como sobremesa, quando deveria considerá-lo como um suplemento alimentar. Muitos desconhecem que o teor de vitamina $\mathrm{C}$, no fruto fresco, está entre 26,6 e $30 \mathrm{mg} / 100 \mathrm{~g}$, é rico em carotenóides, que são antioxidantes, estimuladores das funções imunológicas e protetores de determinados tipos de câncer (MEDEIROS \& RASEIRA, 1998).

Na safra 97/98, os produtores de pêssego da região metropolitana de Porto Alegre comercializaram as frutas de maturação precoce a $\mathrm{R} \$$ $0,60-0,70 / \mathrm{kg}$. Alguns produtores, em determinadas áreas desta região, conseguiram comercializar estas mesmas variedades de pêssego uma semana antes, a $\mathrm{R} \$ 1,70 / \mathrm{kg}$, correspondendo a um incremento de mais de $100 \%$ no preço da fruta (MARODIN, 2000).

A produção de frutas com elevado padrão de qualidade, com bom tamanho, aparência e sabor, é um dos fatores mais importantes no êxito comercial de pomares de frutas de caroço para o consumo "in natura" (ILHA, 1997). Aliado a isto, a coloração e o tamanho final são fatores determinantes da qualidade das frutas de caroço, ao ponto de terem sido convertidos nos parâmetros decisivos para indicação da colheita. A introdução de novas variedades é, talvez, a forma mais rápida e econômica de atingir o objetivo de antecipação de colheita. Por outro lado, a utilização de técnicas como a aplicação de auxinas e a incisão anelar em ramos, podem influenciar positivamente ambos os caracteres (AGUSTÍ et al., 1994).

Vários estudos têm sido realizados na Espanha com frutos de caroço como pêssegos, nectarinas, cerejas e damasco (AGUSTÍ et al., 1995, 1996, 1998 e 1999) e AGUSTÍ, 2000), onde se verifica que o uso de 3,5,6 -TPA (ácido 3,5,6tricloropiridiloxiacético) na formulação ácido livre e 2,4DP (ácido 2,4-diclorofenoxipropiônico) na formulação éster, em concentrações que variam de 10 a $25 \mathrm{mg} \mathrm{L}^{-1}$, respectivamente, têm incrementado o tamanho e a coloração das frutas e antecipado a colheita. No Rio Grande do Sul, em plantas de pessegueiro "Chiripá" com 6 anos de idade, SOUZA et al. (1998) constataram que o uso de 2,4-DP proporcionou um aumento do diâmetro e a antecipação da colheita das frutas.

A auxina é transportada via tecido floemático ou parenquimático de forma polar por transporte ativo e/ou facilitado, fluxo de massa e difusão facilitada (FISHMAN \& GÉNARD, 1998). Esta estimula a extensão da parede celular, e a entrada de água torna o potencial hídrico mais negativo que a solução que a circunda havendo expansão celular das paredes, de modo que o potencial de pressão que se requer para forçar a expansão, nunca retorne de uma forma rápida quanto em células não tratadas (SALISBURY \& ROSS, 1996).

A diferença entre a incisão anelar e o anelamento de ramos foi estudada por AGUSTÍ et al., 1998. A incisão anelar foi realizada nos ramos principais com uma tesoura de lâmina curva formando um ângulo de $360^{\circ}$ na circunferência do tronco. Ela apresentou vantagens por proporcionar maior agilidade de mãode-obra, diminuindo os custos de produção, além de provocar menores danos às plantas. $\mathrm{O}$ anelamento consiste em retirada de um anel de $5 \mathrm{~mm}$ de espessura em toda a circunferência, interrompendo temporariamente o transporte de fluído floemático da copa para as raízes. A incisão anelar proporcionou resultados semelhantes ao anelamento e a vantagem de ser de fácil execução em comparativo com o anelamento.

O objetivo deste trabalho foi avaliar a eficiência de duas auxinas de síntese e a incisão anelar 
em ramos na produção, qualidade e antecipação da maturação do pessegueiro 'Sentinela'.

\section{MATERIAL E MÉTODOS}

O experimento foi realizado em um pomar de pessegueiros adultos de 11 anos da cv. Sentinela de epiderme vermelha, caroço livre e de maturação precoce, de polpa branca e fundente. As plantas estavam espaçadas em 3,5 x 6,0m e localizadas na Estação Experimental Agronômica da UFRGS (Eldorado do Sul, RS), em solo classificado como Podzólico Vermelho Amarelo e declive médio estimado em cerca de $10 \%$. O clima é considerado Cfa da classificação climática de Köeppen ou seja, subtropical úmido com verão quente, caracterizado por apresentar temperatura média do mês mais quente de $22^{\circ} \mathrm{C}$ e temperatura média do mês mais frio de $13^{\circ} \mathrm{C}$.

Os tratamentos foram efetuados na fase de lignificação do endocarpo - estádio II- (17/09/1999), em plantas previamente submetidas ao raleio manual de frutas com os seguintes tratamentos: 1) 3,5,6-TPA $10 \mathrm{mg} \mathrm{L}^{-1}$; 2) 3,5,6-TPA $20 \mathrm{mg} \mathrm{L}^{-1}$; 3) 3,5,6-TPA $30 \mathrm{mg} \mathrm{L}^{-}$ ${ }^{1}$; 4) 3,5,6-TPA $20 \mathrm{mg} \mathrm{L}^{-1}+$ incisão anelar; 5) 2,4-DP 25 $\mathrm{mg} \mathrm{L}^{-1}$; 6) 2,4-DP $50 \mathrm{mg} \mathrm{L}^{-1}$; 7) 2,4-DP $75 \mathrm{mg} \mathrm{L}^{-1}$; 8) 2,4DP $50 \mathrm{mg} \mathrm{L}^{-1}+$ incisão anelar; 9) incisão anelar e 10) Testemunha. A incisão anelar foi efetuada na altura mediana das pernadas principais, mediante o emprego de uma tesoura especial de lâmina curva. As aplicações de fitorreguladores foram executadas mediante o emprego de pulverizador costal, gastando-se 1,25 litros de calda por planta, pulverizando as frutas até o ponto de molhamento completo.

As adubações, tratamentos fitossanitários e demais práticas culturais comumente utilizadas na região foram uniformes para todas as plantas. Do raleio até a colheita foram feitas medições do diâmetro das frutas, nas regiões sutural e não sutural (10 frutos marcados por planta), acompanhando o crescimento do fruto. Estes dados também foram utilizados para analisar o alongamento do fruto na região sutural, usando-se as diferenças entre os diâmetros da região sutural e não sutural. Durante o período de colheita, as frutas de cada árvore foram pesadas, obtendo-se peso total e peso médio e contados, determinando-se a porcentagem de colheita em cada data. Amostras de 10 frutas foram coletadas aleatoriamente das caixas de coleta para a determinação dos sólidos solúveis totais (SST), por meio de refratômetro manual.

O delineamento experimental foi de blocos casualizados com 10 tratamentos, quatro repetições e uma planta por parcela. Com os dados obtidos foram feitas análises de variância e uso do teste de Duncan ao nível de significância de 5\%.

\section{RESULTADOS E DISCUSSÃO}

Não foram encontradas diferenças significativas na produção de frutas para o peso total de frutos por planta (Tabela 1). Já as maiores concentrações de auxinas proporcionaram um aumento no peso médio do fruto em torno de 10 a $15 \%$,

Tabela 1 - Peso médio, peso total, número de frutos por planta e teor de sólidos solúveis totais de pêssegos da cultivar Sentinela submetidos a dois tratamentos de auxinas e incisão anelar dos ramos na EEA/UFRGS, 1999.

\begin{tabular}{|c|c|c|c|c|}
\hline Tratamentos & $N^{\circ}$ frutos/planta & Peso total (kg/pl) & Peso médio (g) & $\mathrm{SST}^{2}$ ( $\left.{ }^{\circ} \mathrm{Brix}\right)$ \\
\hline $10 \mathrm{mg} \mathrm{L}^{-1} 3,5,6-\mathrm{TPA}$ & $760^{\mathrm{ns}}$ & $36,55^{\mathrm{ns}}$ & $46,15 \mathrm{ab}^{1}$ & $7,41 b^{1}$ \\
\hline $20 \mathrm{mg} \mathrm{L}^{-1} 3,5,6-\mathrm{TPA}$ & 665 & 34,78 & $48,95 \mathrm{ab}$ & $8,49 a b$ \\
\hline $30 \mathrm{mg} \mathrm{L}^{-1} 3,5,6-\mathrm{TPA}$ & 753 & 39,80 & $52,20 \mathrm{a}$ & $7,54 \mathrm{ab}$ \\
\hline $20 \mathrm{mg} \mathrm{L}^{-1}$ 3,5,6-TPA + Anel. & 680 & 31,90 & $46,10 \mathrm{ab}$ & $8,37 \mathrm{ab}$ \\
\hline $25 \mathrm{mg} \mathrm{L}^{-1} 2,4-\mathrm{DP}$ & 686 & 33,79 & $49,40 \mathrm{ab}$ & $8,02 \mathrm{ab}$ \\
\hline $50 \mathrm{mg} \mathrm{L}^{-1} 2,4-\mathrm{DP}$ & 779 & 34,47 & $45,00 \mathrm{~b}$ & $8,19 \mathrm{ab}$ \\
\hline $75 \mathrm{mg} \mathrm{L}^{-1} 2,4-\mathrm{DP}$ & 689 & 33,03 & $46,65 \mathrm{ab}$ & $8,67 \mathrm{a}$ \\
\hline $50 \mathrm{mg} \mathrm{L}^{-1}$ 2,4-DP + Anel. & 602 & 31,65 & $50,15 \mathrm{a}$ & $7,76 \mathrm{ab}$ \\
\hline Anelamento & 709 & 39,59 & $52,50 \mathrm{a}$ & $7,62 \mathrm{ab}$ \\
\hline Testemunha & 720 & 37,70 & $49,35 \mathrm{ab}$ & $7,75 \mathrm{ab}$ \\
\hline Média & 705 & 35,33 & 49,00 & 9,10 \\
\hline CV \% & 20,80 & 23,40 & 8,20 & 9,06 \\
\hline
\end{tabular}

${ }^{1}$ Médias não seguidas por mesma letra, nas colunas, diferem entre si a $5 \%$ de probabilidade de erro, pelo teste de Duncan. ns: não significativo ao teste $\mathrm{F}$.

${ }^{2} \mathrm{SST}$ : sólidos solúveis totais

Ciência Rural, v. 33, n. 2, mar-abr, 2003. 
comparados com a testemunha, concordando com os resultados encontrados por (AGUSTÍ et al., 1996) indicando que as auxinas possuem efeito direto sobre o aumento do peso médio do fruto.

Para a incisão anelar, em relação ao peso médio das frutas houve um incremento comparado aos demais tratamentos, dados também encontrados por ILHA, 1997 e AGUSTÍ et al., 1998 (Tabela 1) na qual a incisão anelar realizada após o raleio de frutos possui efeito de reter os carboidratos na parte superior da incisão, drenando principalmente para os frutos em crescimento.

A época de colheita foi influenciada pelos tratamentos aplicados (Tabela 2). Houve uma antecipação de colheita média de $30 \%$ com aplicação $30 \mathrm{mg} \mathrm{L}^{-1}$ de 3,5,6-TPA ou $20 \mathrm{mg} \mathrm{L}^{-1}$ de 3,5,6-TPA + Incisão anelar, em relação à testemunha, para as colheitas de 19 a 22 de novembro. Para o 2,4-DP a resposta foi mais expressiva na concentração isolada de $75 \mathrm{mg} \mathrm{L}^{-1}$. Sua combinação com incisão anelar não incrementou a antecipação. Dados estão em concordância com (AGUSTÍ et al. 1994, 1996 e 1999; AGUSTÍ, 2000) onde ocorreram antecipações de até 10 dias, quando foram utilizadas concentrações de $25 \mathrm{mg}$ $\mathrm{L}^{-1}$ de 2,4-DP e $10 \mathrm{mg} \mathrm{L}^{-1}$ de 3,5,6-TPA em cultivares de pêssegos. Esta antecipação de colheita é conseqüência do estímulo provocado sobre o desenvolvimento do fruto, alcançando antes o climatério. A produção de etileno, em função dos tratamentos com auxinas, é antecipada. Isto se deve ao estímulo provocado pela auxina sobre a atividade da ACC-oxidase, enzima capaz de formar etileno, utilizando o ACC (ácido-1aminociclopropano-1-carboxílico) como substrato.

A incisão anelar não foi marcante na antecipação de colheita (Tabela 2), contrariando algumas observações de ILHA (1997 e AGUSTÍ et al. (1998) onde a prática teve resultados promissores em ameixas e pessegueiros, respectivamente.

O teor de sólidos solúveis totais não foi afetado de forma clara pela aplicação de auxinas e incisão anelar para os frutos (Tabela 1). Isto está em consonância com a maioria dos trabalhos encontrados principalmente na Espanha (AGUSTÍ et al., 1994, 1996 e 1999) e (AGUSTÍ, 2000).

O diâmetro sutural e não sutural (Tabela 3) também não foi afetado de forma marcante nas avaliações finais, mas na primeira medição, cerca de sete dias após a aplicação, as maiores concentrações do 3,5,6-TPA, assim como $50 \mathrm{mg} \mathrm{L}^{-1}$ de 2,4-DP, com ou sem a incisão anelar, proporcionaram frutos com maior diferença entre os diâmentros sutural e não sutural (Tabela 3). Isto foi observado nas duas primeiras avaliações, 7 e 17 dias após a aplicação, os tratamentos com 30 e $75 \mathrm{mg} \mathrm{L}^{-1}$ de 2,4-DP proporcionaram frutas com uma certa deformação. Já por ocasião da colheita as diferenças entre os tratamentos não foram significativos, mas os referidos tratamentos detinham os maiores valores de diferença entre os diâmetros que visualmente eram percebidos. Nas figuras 1 e 2 , observa-se que o maior pico de crescimento do fruto

Tabela 2 - Porcentagens de colheita em três datas da cultivar Sentinela submetidos a dois tratamentos de auxinas e incisão anelar dos ramos na EEA/UFRGS, 1999.

\begin{tabular}{|c|c|c|c|}
\hline \multirow{2}{*}{ Tratamentos } & \multicolumn{3}{|c|}{ Porcentagem } \\
\hline & 19 a $22 / 10$ & 28 a $29 / 10$ & 05/Nov \\
\hline $10 \mathrm{mg} \mathrm{L}^{-1} 3,5,6-\mathrm{TPA}$ & $37,25 a b c^{1}$ & $57,75 \mathrm{ab}^{1}$ & $5,00^{\text {ns }}$ \\
\hline $20 \mathrm{mg} \mathrm{L}^{-1} 3,5,6-\mathrm{TPA}$ & $44,25 \mathrm{ab}$ & $54,00 \mathrm{abc}$ & 2,00 \\
\hline $30 \mathrm{mg} \mathrm{L}^{-1} 3,5,6-\mathrm{TPA}$ & $49,25 \mathrm{a}$ & $40,50 \mathrm{c}$ & 10,25 \\
\hline $\begin{array}{l}20 \mathrm{mg} \mathrm{L} \mathrm{L}^{-1} 3,5,6-\mathrm{TPA}+ \\
\text { Anel. }\end{array}$ & $53,00 \mathrm{a}$ & $43,75 \mathrm{bc}$ & 3,00 \\
\hline $25 \mathrm{mg} \mathrm{L}^{-1} 2,4-\mathrm{DP}$ & $22,00 \mathrm{c}$ & $66,25 \mathrm{a}$ & 11,75 \\
\hline $50 \mathrm{mg} \mathrm{L}^{-1} 2,4-\mathrm{DP}$ & $37,50 \mathrm{abc}$ & $59,25 \mathrm{ab}$ & 3,25 \\
\hline $75 \mathrm{mg} \mathrm{L}^{-1} 2,4-\mathrm{DP}$ & $46,75 \mathrm{a}$ & $48,75 \mathrm{bc}$ & 4,75 \\
\hline 50ppm 2,4-DP + anel. & $34,00 \mathrm{abc}$ & $59,50 \mathrm{ab}$ & 6,25 \\
\hline Anelamento & $24,25 \mathrm{bc}$ & $65,75 \mathrm{a}$ & 10,00 \\
\hline Testemunha & $19,75 \mathrm{c}$ & $69,00 \mathrm{a}$ & 11,25 \\
\hline Média & 37,0 & 56,5 & 6,75 \\
\hline CV \% & 36,37 & 17,59 & 10,58 \\
\hline
\end{tabular}

${ }^{1}$ Médias não seguidas por mesma letra, nas colunas, diferem entre si a $5 \%$ de probabilidade de uso, pelo teste de Duncan. ns: não significativo ao teste $\mathrm{F}$. 
Tabela 3 - Diferenças entre os diâmetros (cm) nas Regiões sutural e não sutural, em três datas de avaliação, de pêssegos da cultivar Sentinela submetidos a dois tratamentos de auxinas e incisão anelar dos ramos na EEA/UFRGS, 1999.

\begin{tabular}{|c|c|c|c|}
\hline \multirow{2}{*}{ Tratamentos } & \multicolumn{3}{|c|}{ Diferença entre diâmetro sutural e não sutural } \\
\hline & 24/Set & $05 /$ Out & 29/Out \\
\hline $10 \mathrm{mg} \mathrm{L}^{-1} 3,5,6-\mathrm{TPA}$ & $0,25 \mathrm{bc}^{1}$ & $0,35 \mathrm{abc}^{1}$ & $0,29^{\mathrm{ns}}$ \\
\hline $20 \mathrm{mg} \mathrm{L}^{-1} 3,5,6-\mathrm{TPA}$ & $0,30 \mathrm{ab}$ & $0,35 \mathrm{abc}$ & 0,27 \\
\hline $30 \mathrm{mg} \mathrm{L}^{-1} 3,5,6-\mathrm{TPA}$ & $0,34 \mathrm{a}$ & $0,42 \mathrm{a}$ & 0,38 \\
\hline $20 \mathrm{mg} \mathrm{L}^{-1} 3,5,6-\mathrm{TPA}+$ Anel. & $0,27 \mathrm{bc}$ & $0,36 \mathrm{abc}$ & 0,36 \\
\hline $25 \mathrm{mg} \mathrm{L}^{-1} 2,4-\mathrm{DP}$ & $0,27 \mathrm{bc}$ & $0,30 \mathrm{bc}$ & 0,32 \\
\hline $50 \mathrm{mg} \mathrm{L}^{-1} 2,4-\mathrm{DP}$ & $0,31 \mathrm{ab}$ & $0,37 \mathrm{abc}$ & 0,29 \\
\hline $75 \mathrm{mg} \mathrm{L}^{-1} 2,4-\mathrm{DP}$ & $0,27 \mathrm{bc}$ & $0,39 \mathrm{ab}$ & 0,41 \\
\hline $50 \mathrm{mg} \mathrm{L}^{-1}$ 2,4-DP + Anel. & $0,29 \mathrm{ab}$ & $0,37 \mathrm{abc}$ & 0,33 \\
\hline Anelamento & $0,26 \mathrm{bc}$ & $0,30 \mathrm{bc}$ & 0,26 \\
\hline Testemunha & $0,23 \mathrm{c}$ & $0,27 \mathrm{c}$ & 0,19 \\
\hline Média & 0.28 & 0,35 & 0,31 \\
\hline CV \% & 14,67 & 18,55 & 23,47 \\
\hline
\end{tabular}

${ }^{1}$ Médias não seguidas por mesma letra, nas colunas, diferem entre si a $5 \%$ de probabilidade de uso, pelo teste de Duncan. ns: não significativo ao teste $\mathrm{F}$.

ocorre por volta de 25 dias após a aplicação, quando os tratamentos com $30 \mathrm{mg} \mathrm{L}^{-1}$ de 3,5,6-TPA e $75 \mathrm{mg} \mathrm{L}^{-1}$ de 2,4-DP proporcionaram maiores diferenças entre os diâmetros sutural e não sutural, corroborando com resultados encontrados por AGUSTÍ et al. (1996). Sabese que, nesta fase, ocorre a lignificação do endocarpo.

\section{CONCLUSÕES}

Os tratamentos com auxinas não alteraram o peso total de frutos por planta e o peso médio.

A incisão anelar de ramos incrementou o peso médio das frutas.

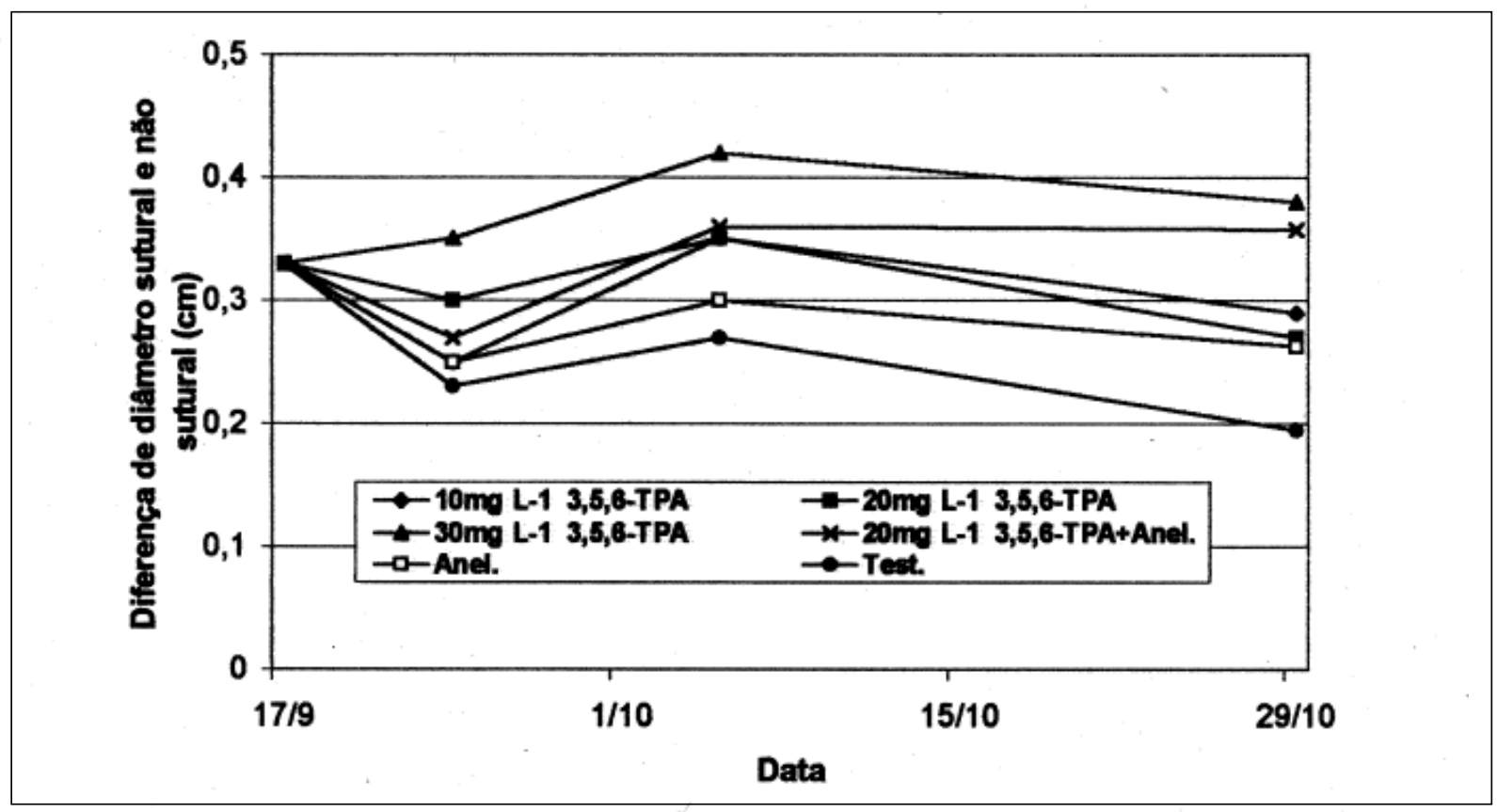

Figura 1 - Diferença sutural e não sutural de frutos de pessegueiros da cv. Sentinela com 10, 20, $30 \mathrm{mg} \mathrm{L}^{-1}$ de 3,5,6-TPA, $20 \mathrm{mg} \mathrm{L}^{-1}$ de 3,5,6TPA + incisão anelar, incisão anelar de ramos e testemunha, na EEA-UFRGS, Eldorado do Sul-RS, 1999.

Ciência Rural, v. 33, n. 2, mar-abr, 2003. 


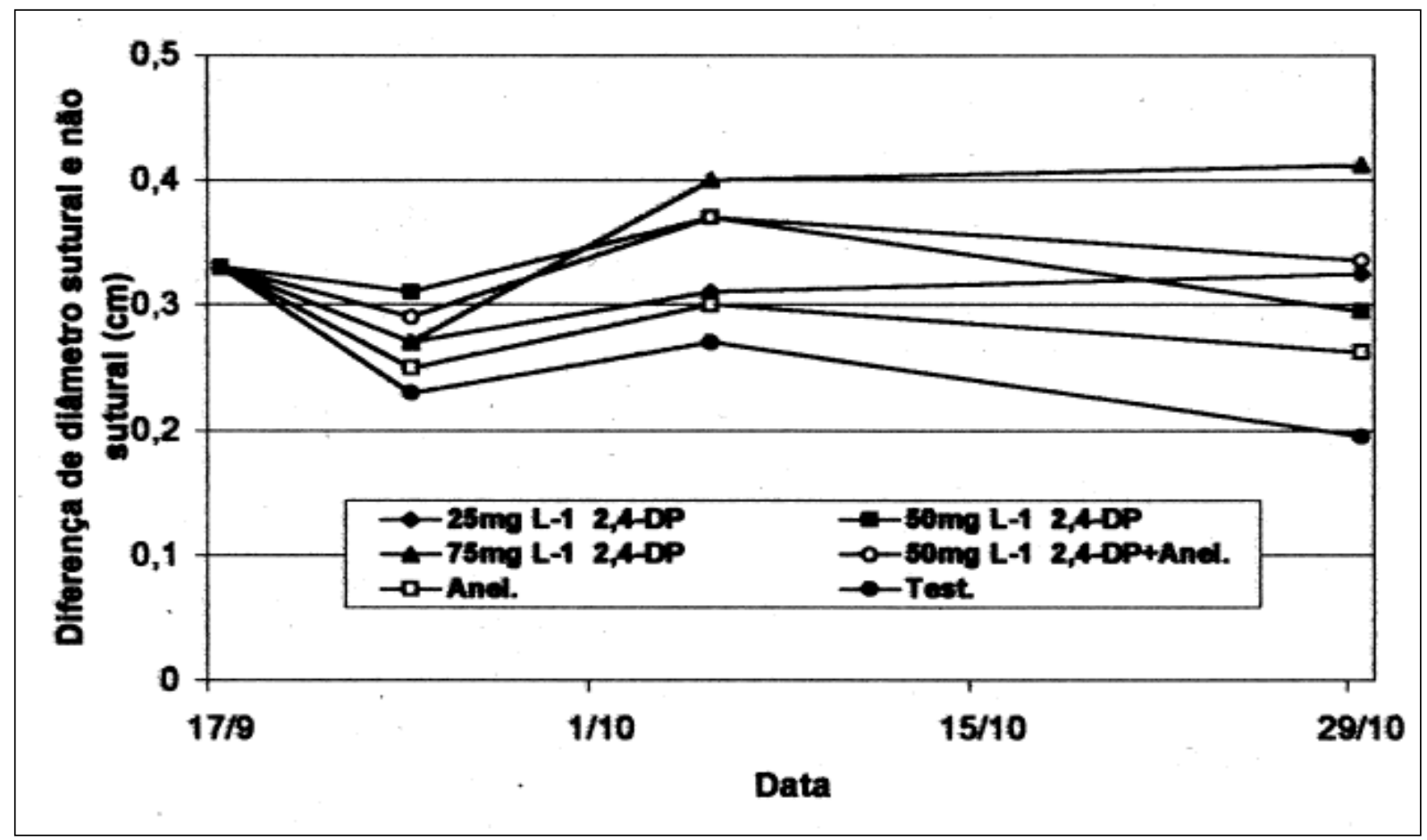

Figura 2 - Diferença sutural e não sutural de frutos de pessegueiros da cv. Sentinela com concentrações de $25,50,75 \mathrm{mg} \mathrm{L}^{-1}$ de 2,4-DP, 75 $\mathrm{mg} \mathrm{L}^{-1}$ de 2,4-DP + incisão anelar de ramo, incisão anelar de ramos e testemunha, na EEA-UFRGS, Eldorado do Sul- RS, 1999.

Os tratamentos com auxinas, especialmente $20 \mathrm{mg} \mathrm{L}^{-1}$ de 3,5,6-TPA com ou sem incisão anelar, 30 $\mathrm{mg} \mathrm{L}^{-1}$ de 3,5,6-TPA e $75 \mathrm{mg} \mathrm{L}^{-1}$ de 2,4-DP anteciparam a colheita em cerca de 15 dias;

Os tratamentos não afetaram a qualidade dos frutos em termos de sólidos solúveis totais.

\section{REFERÊNCIASBIBLIOGRÁFICAS}

AGUSTÍ, M. et al. Estímulo del desarrollo de los frutos de hueso mediante la aplicación de 2, 4-DP. Fruticultura Profesional, Barcelona, n.60, p.5-16, 1994.

AGUSTÍ, M. et al. Mejora de la calidad del fruto de melocotoneros y albaricoqueros mediante la aplicación de auxinas de síntesis. Valencia : Generalitat Valenciana, 1995. 19p.

AGUSTÍ, M. et al. Estímulo del desarrollo de los frutos de hueso. Valencia : Generalitat Valenciana, 1996. 78p.

AGUSTÍ, M. et al. Effects of ringing branches on fruit size and maturity of peach and nectarine cultivars. Journal of Horticultural Science \& Biotechnology, Valencia, v.73, n.4, p.537-540, 1998

AGUSTÍ, M. et al. Synthetic auxin 3,5,6-TPA promotes fruit development and climacteric in Prunus persica L. Batsch. Journal of Horticultural Science \& Biotechnology, Valência, v.74, n.5, p.556-560, 1999.
AGUSTÍ, M. Alternativa de manejo de frutas de caroço e antecipação de colheita mediante utilização de auxinas de síntese. In: SIMPÓSIO INTERNACIONAL DE FRUTAS DE CAROÇO: PÊSSEGOS, NECTARINAS E AMEIXAS, 1., 2000, Porto Alegre. Anais... Porto Alegre : UFRGS-DHS, 2000. p.71-83.

FAO. FAOSTAT. Database results. Rome. Disponível em http://www.Fao.2000. Acesso em 14 jun. 2001.

FISHMAN, S.; GÉNARD, M. A biophysical model of fruit growth: simulation of seasonal and diurnal dynamics of mass. Plant Cell and Environment, Bet Dagan, v. 21, p. 739-752, 1998.

ILHA, L.L.H. Intensidades de raleio manual e anelamento do tronco em ameixeira japonesa (Prunus salicina Lindley) cultivar amarelinha. 1997. $124 \mathrm{p}$. Dissertação (Mestrado em Fitotecnia) - Faculdade de Agronomia, Programa de Pós-graduação em Agronomia, Universidade Federal do Rio Grande do Sul.

MARODIN, G.A.B.; SARTORI, A.S. Situação das frutas de caroço no Brasil e no mundo. In: SIMPÓSIO INTERNACIONAL DE FRUTAS DE CAROÇO: PÊSSEGOS, NECTARINAS E AMEIXAS, 1., 2000, Porto Alegre. Anais... Porto Alegre : UFRGS-DHS, 2000. p.7-16.

MARODIN, G.A.B. Jornal Zero Hora. Campo e Lavoura. Porto Alegre. Sexta-feira, 25 fev. 2000.

MEdeIROS, C.A.B; RASEIRA, M. do C.B. A Cultura do pessegueiro. Pelotas : Embrapa-CPACT, 1998. 350p. il. 
SALISBURY, F.B.; ROSS, C.W. Fisiologia vegetal. México, D.F.: Grupo Editorial Iberoamérica, 1996. 759p.

SOUZA, P.V.D., MARODIN, A.; B. SEIBERT, E. Efeito de auxinas e incisão anelar nos ramos sobre o diâmetro e antecipação da colheita em pessegueiros cultivar chiripá. In: CONGRESSO BRASileiro De FRUTiCUlTURA, 15., 1998, Poços de Caldas. Resumos... Poços de Caldas : SBF, 1998. p.687. 